\title{
Organik patolojisi olmayan, globus farengeus ile başvuran hastaların değerlendirilmesi
}

\section{Evaluation of patients presenting with globus pharyngeus, with no organic pathology}

\author{
Fatma Çaylaklı@, Haluk Yavuz (iD)
}

Başkent Üniversitesi Tıp Fakültesi, Kulak Burun Boğaz Anabilim Dall, Ankara, Türkiye

\section{$\ddot{O} Z$}

Amaç: Bu çalışmada globus farengeus ile başvuran hastalarda altta yatan herhangi bir kötü hastalık olasılığının elenerek hastaların endişelerinin giderilmesinin uzun dönemde yakınmalarının devamlılığı üzerine etkisi araştırıldı.

Hastalarve Yöntemler: Çalışmaya Ocak 1999 - Aralık 2014 tarihleri arasında boğazında bir şey varmış hissi ile kliniğimize başvuran ve baryumlu farengoözefagografi, boyun ultrasonografisi veya bilgisayarlı tomografi ile değerlendirilen 57 hasta (19 erkek, 38 kadın; ort. yaş $39.5 \pm 12$ yıl) dahil edildi. Hastalarla telefon görüşmesi ile temasa geçildi ve yakınmalarının devam edip etmediği sorguland.

Bulgular: Toplam 44 hastanın (\%77; 11 erkek, 33 kadın) yakınması geçti. Erkeklerin \%58'inin ve kadınların \%87'sinin yakınması geçerken aradaki farklılık istatistiksel olarak anlamlıydı $(\mathrm{p}<0.05)$. Hastaların başvuru sırasındaki yakınma süreleri bir yıldan kısa (kısa süreli) ve bir yıldan uzun (uzun süreli) şeklinde sınıflandırıldı. Kısa süreli yakınması olan grubun \%71'inin (12/17) yakınması geçerken uzun süreli yakınması olan grubun \%80'inin (32/40) yakınması geçti. Hastaların başvuru sırasındaki yakınma süreleri yakınmanın geçip geçmemesi üzerinde etkili değildi ( $p>0.05)$.

Sonuç: Organik bir patolojiye bağlı bulunmayan globus farengeus yakınmasında, altta yatan kötü bir hastalık olmadığının saptanarak endişenin giderilmesi hastaların yakınmalarının geçmesi üzerinde olumlu etkiye sahipti.

Anahtar sözcükler: Kanser; globus farengeus; organik; patoloji.

\begin{abstract}
Objectives: This study aims to investigate the effect of resolving the anxieties of patients applying with globus pharyngeus by eliminating the possibility of any underlying malignant disease on the continuation of their complaints in the long-term.
\end{abstract}

Patients and Methods: The study included 57 patients (19 males, 38 females; mean age $39.5 \pm 12$ years) who admitted to our clinic between January 1999 and December 2014 with a sensation of something in their throat and who were evaluated with barium pharyngoesophagography, neck ultrasonography or computed tomography. Patients were contacted by telephone and questioned about whether or not their complaints continued.

Results: Complaints of a total of 44 patients (77\%; 11 males, 33 females) faded. While complaints of $58 \%$ of males and $87 \%$ of females faded, the difference in between was statistically significant $(\mathrm{p}<0.05)$. We classified the complaint durations of patients on admission as shorter than one year (short-term) and longer than one year (long-term). While complaints faded in $71 \%(12 / 17)$ of the group with short-term complaints, complaints faded in $80 \%$ (32/40) of the group with long-term complaints. Complaint durations of patients on admission were not effective on the fading of the complaints ( $>0.05)$.

Conclusion: In the globus pharyngeus complaint that does not relate to any organic pathology, resolving the anxiety by detecting the non-existence of any underlying malignant disease had a positive effect on the fading of patients' complaints.

Keywords: Cancer; globus pharyngeus; organic; pathology. 
Globus farengeus, boğazda yabancı bir madde varmış hissi şeklinde tanımlanıp Kulak Burun Boğaz hekimlerine başvuranların şikayetlerinin \%4'ünü oluşturur. Etyolojisinde somatik bozuklukların rol oynadığı varsay1larak bu semptom daha önceleri "globus histerikus" olarak adlandırılmış ancak son yıllarda yapılan çalı̧̧malarda üst sindirim sistemine ait hastalıkların da globus semptomuna neden olabileceği anlaşılmıştır. ${ }^{[1-3]}$ Bunun yanı sıra üst gastrointestinal sistem malignitelerine de rastlanmaktadır. Klinik olarak bu şikayetle başvuran çoğu hastanın başvuru nedeni altında kanser olma korkusunun yer aldığını görmekteyiz. Biz bu çalı̧̧mada globus farengeus şikayeti ile başvuran hastaların klinik ve radyolojik değerlendirme sonrasında altta yatan kötü bir hastalığ1 olup olmadığını araştırarak, bu durumun ekarte edilip hastaların endişelerinin ortadan kaldırılması ve bunun da hastaların uzun dönem takiplerinde şikayetlerinin devam edip etmediği üzerine etkisini değerlendirmek istedik.

\section{HASTALAR VE YÖNTEMLER}

$\mathrm{Bu}$ çalışma retrospektif klinik bir çalışma olup Başkent Üniversitesi Tip ve Sağlık Bilimleri Araştırma Kurulu ve Etik Kurulu tarafından onaylanmıştır (Proje no: KA 16/183). Çalışmamıza, Ocak 1999 - Aralık 2014 tarihleri arasında boğazında bir şey varmış hissi ile kliniğimize başvuran ve baryum farengoözefagografi, boyun ultrasonografisi (USG) veya boyun bilgisayarlı tomografisi (BT) ile değerlendirilen hastalar dahil edildi. Bilinen farengeal ve özofageal hastalığı, farengeal veya özofageal disfonksiyona neden olan nörolojik hastalığı, otoimmün hastalığı olanlarla, diabetes mellitusu, geçmişte baş boyunda cerrahi girişimi ve tiroid ameliyatı öyküsü olanlar ve radyolojik incelemelerde tiroid nodülü ve boyunda kitle tespit edilen hastalar çalışmaya dahil edilmedi. Çalışma kriterlerine uygun olan hastalar telefon ile aranarak şikayetlerinin devam edip etmediği sorguland.

\section{BULGULAR}

Çalışmada kliniğimizde baryumlu farengoözefagografi çekilen 1915 hastanın dosyaları retrospektif olarak değerlendirildi. Çalışma kriterlerine 92 hasta uymaktaydi. Ancak telefon ile ulaşılabilen ve çalışmaya katılmayı kabul eden 57 hasta (19 erkek, 38 kadın; ort. yaş 39.5 \pm 12 yıl) çalı̧̧maya dahil edildi. Kırk dört hastanın (\%77) (11 erkek, 33 kadın) şikayeti geçmiş ve herhangi bir sorunu kalmamıştı. Cinsiyet açısından karşılaş̧ıııldığında erkekler arasında şikayet geçme oranı $\% 58$ (11/19), kadınlar arasında ise \%87 (33/38) idi. Aradaki fark anlamlıyd 1 $(p<0.05)$. Hastaların başvuru esnasındaki şikayet süreleri bir yıldan az ise (k1sa süreli), bir yıldan fazla ise (uzun süreli) şeklinde sınıflandırıldı. Buna göre kısa süreli şikayeti olan hasta sayısı 17 , uzun süreli şikayeti olan hasta sayısı ise 40 idi. Kısa süreli şikayeti olan grupta şikayeti geçenlerin sayısı 12 (\%71), uzun süreli şikayeti olan grupta şikayeti geçenlerin sayısı $32(\% 80)$ idi. Hastaların başvuru sırasındaki şikayet sürelerinin, şikayet geçip geçmeme üzerine etkisinin olmadı̆̆ $\breve{1}_{\text {saptand }}$ ( $\left.p>0.05\right)$. Hastaların 13'ünde (\%23) (9 kadın, 4 erkek) gastroözefageal reflü bulguları vard.

\section{TARTIŞMA}

Globus farengeusa neden olan birçok etyolojik etken bulunmaktadır. Psikolojik faktörlerin ${ }^{[4]}$ yanı sıra farengeal dismotilite, ${ }^{[5]}$ üst özofageal sfinkter hipertonisisitesi, ${ }^{[6]}$ gastroözofageal reflü, ${ }^{[7,8]}$ tiroid hastalıkları, ${ }^{[9]}$ lokal anatomik bozukluklar ${ }^{[10,11]}$ da etyolojide yer almaktadır. Çalışmaların çoğunda hastaların \%60'ını kadınlar oluşturmaktadır. ${ }^{[12]}$ Bizim çalışmamızda da hastaların çoğunluğunu (\%67) kadınlar oluşturmaktaydı. Stres bulguları tetikleyici faktör olabilir. Yakınlarını kanser nedeniyle kaybeden hastalarda bu endişe daha fazla olmaktadır. Globus farengeus şikayeti ile başvuran çoğu hasta şikayetlerini bile tam ifade edememektedir. Birçoğunda altta yatan kanser olma korkusu yer almakta ancak bunu muayene esnasinda bile dile getirmemektedir. Muayene ve inceleme sonuçları normal olarak sonuçlandığ 1 zaman ancak bu korkularını ifade etmektedirler. Baryumlu farengoözefagografi genellikle globus şikayeti ile başvuran hastalarda üst gastrointestinal sistem malignitelerini ekarte etmek için istenmektedir. ${ }^{[12,13]} \mathrm{Biz}$ de çalışmamıza baryumlu farengoözefagografi incelemesi yapılmış olan hastaları dahil ettik. Başvuran hasta çoğunluğunu kadınlar oluşturmakla birlikte şikayeti geçenlere baktığımızda kadınlar yine çoğunluğu oluşturmaktaydı. Muayene ve değerlendirme sonrasında sonuçların normal sınırlar içerisinde bulunmasının hastayı rahatlattığını, altta kötü bir hastalık yatıyor endişesi varsa bu endişenin giderilmesinin şikayetlerin düzelmesinde etken olduğunu düşünmekteyiz. Şikayet sürelerinin uzunluğunun şikayetin geçip geçmemesine etkisi olup olmadığına baktığımızda etkisi olmadığını tespit ettik. Fakat bu sonucun çalı̧̧maya katılanların sayısının azlığından dolayı olduğunu düşünmekteyiz. Değerlere bakıldığında uzun süreli şikayeti olanlarda şikayeti geçme oranı yüksekti. Hasta sayısının daha fazla olduğu çalışmalarda bu sonucun değişebileceğini düşünmekteyiz.

Sonuç olarak, günümüzde birçok hasta kanser ya da kötü bir hastalık korkusu ile kliniklere başvurmaktadır. Çoğu zaman bu korkularını başvuru esnasında belirtmemekte, ancak muayene bittikten sonra ve muayene bulguları doğal olduğunda ifade etmektedir. Globus farengeus şikayeti ile başvuran, altta yatan organik patolojisi bulunmayan hastalarda yaptığımız retrospektif çalışmada hem başvuranların hem de şikayeti geçenlerin çoğunluğunu kadınlar oluşturmakta idi. Organik bir patolojiye bağl1 
bulunmayan globus farengeus şikayetinde, altta yatan kötü bir hastalık olmadığının saptanması ve bu endişenin giderilmesinin hastaların şikayetlerinin geçmesi üzerine olumlu etkisi olduğunu düşünmekteyiz.

\section{Çıkar çakışması beyanı}

Yazarlar bu yazının hazırlanması ve yayınlanması aşamasında herhangi bir çıkar çakışması olmadığını beyan etmişlerdir.

\section{Finansman}

Yazarlar bu yazının araştırma ve yazarlık sürecinde herhangi bir finansal destek almadıklarını beyan etmişlerdir.

\section{KAYNAKLAR}

1. Alaani A, Vengala S, Johnston MN. The role of barium swallow in the management of the globus pharyngeus. Eur Arch Otorhinolaryngol 2007;264:1095-7.

2. Kortequee S, Karkos PD, Atkinson H, Sethi N, Sylvester DC, Harar RS, et al. Management of globus pharyngeus. Int J Otolaryngol 2013;2013:1-5.

3. Mahrous AK, Kaoutzanis C, Amin K, Gluckman P. Positive findings on barium swallow in patients presenting with a "sensation of a lump in the throat". Eur Arch Otorhinolaryngol 2012;269:1047-50.

4. Deary IJ, Wilson JA, Kelly SW. Globus pharyngis, personality, and psychological distress in the general population. Psychosomatics 1995;36:570-7.

5. Chen CL, Tsai CC, Chou AS, Chiou JH. Utility of ambulatory $\mathrm{pH}$ monitoring and videofluoroscopy for the evaluation of patients with globus pharyngeus. Dysphagia 2007;22:16-9.

6. Corso MJ, Pursnani KG, Mohiuddin MA, Gideon RM, Castell JA, Katzka DA, et al. Globus sensation is associated with hypertensive upper esophageal sphincter but not with gastroesophageal reflux. Dig Dis Sci 1998;43:1513-7.

7. Chevalier JM, Brossard E, Monnier P. Globus sensation and gastroesophageal reflux. Eur Arch Otorhinolaryngol 2003;260:273-6.

8. Özgürsoy OB, Özlügedik S, Yorulmaz İ. Globus farengeus etyolojisinde larengofarengeal reflü. KBB ve $\mathrm{BBC}$ Dergisi 2002;10:72-5.

9. Nam IC, Choi H, Kim ES, Mo EY, Park YH, Sun DI. Characteristics of thyroid nodules causing globus symptoms. Eur Arch Otorhinolaryngol 2015;272:1181-8.

10. Agada FO, Coatesworth AP, Grace AR. Retroverted epiglottis presenting as a variant of globus pharyngeus. J Laryngol Otol 2007;121:390-2.

11. Ko MT, Chen HL, Peng JP, Lin TY, Lin WC. Do cervical degenerative diseases associate with foreign body sensation of the pharynx? Dysphagia 2012;27:88-93.

12. Harar RP, Kumar S, Saeed MA, Gatland DJ. Management of globus pharyngeus: review of 699 cases. J Laryngol Otol 2004;118:522-7.

13. Back GW, Leong P, Kumar R, Corbridge R. Value of barium swallow in investigation of globus pharyngeus. J Laryngol Otol 2000;114:951-4. 